\title{
STRATEGIC FLEXIBLE WORKING ARRANGEMENT: THE REALIGNMENT BETWEEN HUMAN RESOURCE AND MANAGEMENT ACCOUNTING
}

\author{
Sharifah Rahama Amirul $^{1 *}$, Sharifah Milda Amirul ${ }^{2}$, Rasid Mail ${ }^{3}$ \\ $1^{*, 2,3}$ Lecturers of Universiti Malaysia Sabah, Malaysia. \\ Email: ${ }^{1 *}$ sra@ums.edu.my, ${ }^{2}$ sma@ums.edu.my, ${ }^{3}$ rmail@ums.edu.my
}

\author{
Article History: Received on $22^{\text {nd }}$ June 2020 , Revised on $15^{\text {th }}$ August 2020 , Published on $17^{\text {th }}$ September 2020
}

\begin{abstract}
Purpose of the study: This paper aims to pioneer the investigation of human resource (HR) and management accounting (MA) realignment in delivering organizational working flexibility strategy. The core idea is to rebranding the HR and MA framework for strategic flexible working arrangements (FWA), so that FWA implementation or enhancement can be both effective and efficient.
\end{abstract}

Methodology: This study is based on the epistemological of the social constructivist approach and qualitative in nature. We conducted semi-structured interviews and analyzed the collected data by using thematic analysis.

Main Findings: The results revealed that HR and MA have overlapping responsibilities that add value to effective and efficient FWA implementation/enhancement. There is a definite prerequisite for HR and MA to sit together to manage employees' performance appraisal, compensation, and benefits. To ensure the efficiency of FWA, HR critically needs MA information such as budgeting, return on investment, variance analysis and, cost monitoring of FWA implementation/enhancement.

Applications of this study: This study provides insight beyond FWA adoption, whereby we proposed a framework for strategic FWA, which bridges the connection between HR and MA so that FWA implementation or enhancement can be both effective and efficient. We thoroughly discussed how the synergy between HR and MA can be achieved through several key elements, which is expected to yield strategic outcomes for the organization. Most importantly, the organization shall be able to overcome the redundancies between HR and MA roles to create a more compelling strategic planning for FWA implementation. Hence, leading towards greater strategic outcomes such as strategic dynamic acquisition, effective HR cost, a strategic link between HR outcomes and business, strategic return on investment, as well as comprehensive HRM measurement and performance.

Novelty/Originality of this study: The study developed a conceptual framework of HR and MA integration and strategic outcomes for FWA implementation. The features of this framework are of greater importance for FWA success and advance the notion of FWA literature by unveiling the strategic alignment between HR and MA.

Keywords: Flexible Working Arrangement (FWA), Human Resource (HR), Management Accounting (MA), Working Flexibility Strategy, Agile Working.

\section{INTRODUCTION}

In recent decades, the demands on flexible work arrangements (FWA) have become a global trend for both fast and emerging market economies. Rapid and technology-dependent redefined business operation and work design into a more flexible arrangement (Burgmann, 2012; Cannon \& Elford, 2017; Clake, 2005; Goga-Cooke, 2012; Thomson, 2008). The provision of technology in organizations gives employees greater opportunities for flexibility in scheduling (Andrejic, 2017). This advancement of technology has coincided with the emergence of global awareness and new open markets but has also necessitated that businesses develop a fast-paced, 24/7 culture (eg. Cannon \& Elford, 2017; Burgmann, 2012, Lake, 2013).

The emergence of a global consciousness that focuses on the needs of employees, customers, and the public at large on the principle of sustainability has led to the evolution of FWA adoption (Cannon \& Elford, 2017). For example, the need for FWA is often associated with the issue of a work-life balance and employees' wellbeing (e.g. Clake, 2005; Downes \& Koekemoer, 2011; Hayman, 2009; Kowalski, 2017; Loon et.al., 2019; Scholarios et.al., 2017). Additionally, FWA facilitates employees with an increased sense of autonomy in both work and home life, leading to a whole range of benefits both mental and physical (Chandola et.al, 2019; Barney \& Elias, 2010). For organizations to be able to remain sustainable, they must promote the wellbeing of their employees to enhance performance, thereby developing as an organization (Currie, 2001).

FWA has been studied by a range of researchers from many related disciplines, and the overwhelming consensus has been that FWA is beneficial to both employees and employers. FWA has consistently been shown to increase employee performance (Caillier, 2018; Coenen \& Kok, 2014; De Menezes \& Kelliher, 2017; Kossek \& Michel, 2010), engagement (Kossek et al., 2010; Lee \& Hong, 2011), productivity (Barney \& Elias, 2010; Hunter, 2019; Kossek et al., 2010; Obisi, 2017; Ollo-lopez \& Bayo-moriones, 2010), reduce turnover (Coenen \& Kok, 2014; Lee \& Hong, 2011), mitigate stress (Kossek et al., 2010), improve employee satisfaction (Barney \& Elias, 2010), reduce absenteeism (Barney \& Elias, 2010; 
Coenen \& Kok, 2014), support employee work/life balance, and improve overall business performance (Richardson \& Mckenna, 2014).

Despite the wealth of benefits that have been attributed to FWA, the flexible working strategy is yet to be well-captured in the current literature of FWA studies. Burgmann (2012) highlighted that the real gap in FWA research lies in how flexible work can become part of an organization's strategy for building on its strengths and taking up new opportunities (Burgmann, 2012). Thompson (2019) argued that the debate over whether FWA should be implemented is now over, the current focus is figuring out ways to get the best results. To effectively integrate FWA into an organization, and therefore reap the above benefits as outlined above, it is critically important for a business to have strategies in place throughout their FWA implementation. Therefore, this paper aims to advance the existing literature on FWA by pioneering the investigation of human resource (HR) and management accounting (MA) intersections in delivering organizational working flexibility strategy. The core idea is to rebranding the HR and the MA framework for strategic FWA so that FWA implementation or enhancement can be both effective and efficient.

Numerous studies (Daft \& Marcic, 2020; Armstrong, 2006; Lewis \& Roper, 2008; Clarke \& Braun, 2015; Society Human Resource Management, 2016; CIPD, 2014) have highlighted the role of HR in managing FWA, but incorporating MA into FWA studies is relatively new, as their integration in the existing literature is rare and still underresearched. HR's role in any organization revolves around managing employees, a crucial factor for FWA (Armstrong, 2006; Clake, 2005; Daft \& Marcic, 2020; Lewis \& Roper, 2008; Society Human Resource Management, 2016; CIPD, 2014;). The challenge of HR contribution in FWA and work-life initiatives to individual and organizational performance are increasingly under pressure since HR professionals are required to demonstrate whether and how these initiatives contribute to effective management in organizations in terms of financial and non-financial, and perceptual indicators of performance (Bell et al., 2012).

Mainly, HR outcomes are focus on the effectiveness of managing people. To make a more convincing strategic FWA plan, the proposition of FWA implementation/enhancement must capture both effective and efficient outcomes. Apart from HR, management accounting (MA) is another key to operative FWA, which can prove the efficiency of FWA in the financial aspect, (Amirul et.al., 2019). MA is concerned with the provisions and use of accounting information to managers within an organization, which provides them with the basis to make informed business decisions that will allow them to be better equipped in their management and control function (Ladda, 2014). MA reports facilitate future cost control, income generation, and managerial decision making (Apostolides, 2016). Investigating the intersection between HR and MA is noting worth to ensure that FWA implementation can be both effective and efficient. If FWA strategies are not implemented from the outset, FWA implementation may not function effectively for the employee or the employer, thereby jeopardizing their implementation and potential benefits in the long run.

\section{LITERATURE REVIEW}

\section{Flexible Working Arrangement (FWA)}

FWA is defined as any policies and practices, formal or informal, which permit people to vary when and where work is carried out (Maxwell et al., 2007). A deliberately arranged FWA has positive impacts on organization related outcomes, such as increased financial performance, productivity, organizational commitment, and job-related wellbeing, and decreased labor turnover and absenteeism (Menezes \& Kelliher, 2011). Some forms of flexible working schedules have been introduced largely to meet employer needs for flexibility or to keep costs down (Stavrou et al., 2010, p.894). The need for FWA is not solely for employees but also for organizational benefits. FWA has the potential to be used as strategies to attract unique capabilities and build competencies for competitive advantage (Kotey, 2017) which may in turn positively affect financial performance (Kotey \& Sharma, 2019).

Despite FWA benefits, there are still many companies that are resisted to embrace FWA because of several reasons. For example, employees were not trusted to manage their own time flexibly and sustain productivity (Lewis \& Roper, 2008). In the same vein, scholars Potter, (2007) asserted that implementation cost also becomes a barrier to FWA realization. Additionally, FWA is also seen as a complicated process and become a burden to management or business owner (Hartel \& Fujimoto, 2014). Hays (2017) further added that many businesses have been able to offer their employees FWA, but business leaders have begun to question if FWA makes good business sense and this has led to cases of reduced flexible working options. CIPD (2014) stressed that negative line management attitudes, as well as the trust issues over the quality of work, produced preventing employees from being given control over when and where they work. For addressing the issue or barrier to FWA implementation, the realignment between HR and MA is expected to create a more convincing strategic framework for FWA implementation.

\section{The Realignment between $H R$ and MA}

HR and MA are two different organizational functions but are essential parts of every business. Nevertheless, the connection between HR and MA are limited and not well-captured in existing literature as it tends to be treated separately (Amirul et.al., 2019). HR can be referred to as the design and application of formal systems in an organization to ensure the effective and efficient use of human talent to accomplish organizational goals. This includes activities undertaken to attract, develop, and maintain an effective workforce (Daft \& Marcic, 2020). While the management 
accounting function exists to provide information to decision-makers and to provide advice based on information that is provided. The information provided by management accounting covers all areas of strategy and operations and includes information to assist with planning, control, and other decision-making by management (CPA Australia, 2012).

HR roles in FWA is very common in existing literature (e.g. Arsmtrong, 2006; Clarke \& Braun, 2015; CIPD, 2014; Daft \& Marcic, 2020; Gilabert, 2008; Kossek et al., 2010; Lewis \& Roper, 2008; Society Human Resource Management, 2016; Kowalski et.al., 2017; Thomson, 2008). The HR professionals are the key in this process who are charged with the operational aspects of implementing FWA to meet strategic goals (Society Human Resource Management, 2016), to support and coach line managers to deal with FWA effectively and to effectively communicate an organization's approach to flexible working to all employees and raise awareness of the business benefits (Clake,2005). Without proper HR planning in implementing FWA may lead to poor decisions and improper work design.

Nevertheless, HR alone will not be enough for the FWA implementation plan. The most convincing FWA plan must be both effective and efficient. HR is about managing people (effectiveness) and MA is important for financial planning and projection (efficiency). Management Accounting (MA) has evolved continuously from merely financially orientated decision analysis to a more broad strategic approach which emphasizes the key financial and operational drivers to create value for shareholders (Kaplan, 2009). While MA concerns on a formulation of strategic goals to achieve long-term business performance, the human resource management (HRM) is arguably playing vital roles in contributing towards organizational performance and competitive advantage (Delery \& Roumpi, 2017; Haque, 2020; Katou, 2017; Vedd \& Kouhy, 2001) through creating a driver for the successful implementation of the strategic human workforce such as FWA.

Zeng (2018) has recently published his work on reciprocal interaction between MA and other management. In his seminal work, Zeng (2018) highlighted that HR and MA need to collaborate to set goals sufficiently within the grasp of employees while simultaneously challenging the employees to develop further. Another latest work by Kotey and Sharma (2019) has investigated the direct and indirect effects of FWA on return on labor (ROL). Their study significantly found that FWA directly increased ROL and indirectly through a reduction in staff turnover (Kotey \& Sharma, 2019). For organizations, such significant findings will be a good indicator, but it will be more compelling if the HR plan in FWA implementation is completed with accounting information prepared by MA.

HR may be able to produce basic financial information but not as profound as MA itself. To have an efficient FWA implementation, HR must look deeper than a percentage of payroll or revenue. HR must understand the largest costs and know precisely how the money is being utilized. In addition to that, understanding what the return on investment is and has a solid justification for HR spending (Bannermant, 2003). MA captured information about overall business functions and performances within an organization, which is reflected through budgeting, performance analysis, and performance indicators both financially and non-financially which is parallel with the technological and environmental changes that affect how businesses are operating today. Hence, the information supplied by MA is recognized as essential for management to make a strategic decision for the success and survival of an organization in a competitive environment (Vedd \& Kouhy, 2001; Saukkonen et al., 2018).

By drawing on the integration between HR and MA, Yoshikawa and Innes (2009) accentuated four vital communication links between HR and MA, those are budgets, strategic plans, performance-related bonus schemes, and decision making. Embedding HR and MA in FWA implementation planning will help the organization to trim workforce and workplace management costs (Amirul et.al., 2019). Accounting information is very important for HR when implementing FWA because accounting information is essential for planning, controlling, decision making, and used for coordination across the organization (Kariyawasam, 2016). As stated by Collier (2009), accounting for labor is not an asset to be shown in a balance sheet, but practically labor is one of the most important assets of a business. In addition to that, there is a need for HR and MA to work together because a lack of expertise in using MA tools could hinder other management like HR to link managerial responsibility (including people management) into financial terms (Saukkonen et al., 2018). A strategic MA approach to HR would be to value (for decision making not reporting) the investment in the knowledge and skills of employees. This might avoid making short-term decisions to make employees redundant (Collier (2009, p.340)

\section{METHODOLOGY}

\section{Philosophical Foundation of Study}

This study is based on the epistemological of the social constructivist approach. Constructivism is a non-positivist paradigm, rather than starting with a theory as in post-positivism, it begins with generating inquiries or inductively develop a theory or pattern of meaning (Creswell, 2009). The constructivist approach emphasized that learning as an active process, new knowledge is constructed or developed from participants current and past understanding, knowledge, and experiences (Creswell, 2009; Orly, 2015; Quintero \& Rosario, 2016) The constructivist view prompts this paper to identify the contextual factors of HR and MA integration to create a more effective and efficient FWA implementation. Using the constructivist epistemological aspect enables this study to build the frame of the research by including qualitative methods and gathering perspectives regarding HR and MA integration in employing FWA. 


\section{Participation Recruitment}

Senior human resource and accounting practitioners were selected based on the purposeful sampling technique because these participants have background, knowledge, and experience with the phenomenon of interest in this study (Cresswell

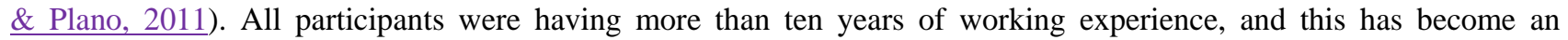
important selection criterion of the study's sample. In a qualitative study, there is no agreed-upon or universally accepted sample size for qualitative research. For this study, the sample size is determined through the principle of saturation, which means the data collection leads to the same information (repeated) and there is a new or additional insight to the information (Crouch \& McKenzie, 2006; Guest et al., 2006). There were ten participants involved in this study, which consist of two HR professionals, four HR professionals with accounting background/experience, and four participants with pure accounting background (3 Accountant, 1 Auditor). From ten interviews, this study has collected enough meaningful information to identify key themes and contributing to a new research framework and recommendations. Dworkin (2012) reported that a tremendous number of literature commonly suggests between five to fifty participants as adequate. A seminal work conducted by Guest et al., (2006) has further supported the sample size of this study. Based on a systematic inductive thematic analysis of 60 in-depth interviews, Guest et al., (2006) study have generated 114 research themes. Of the 114 research themes, 80 research themes $(80 \%)$ were identified from the first six interviews, and the number rises to 100 research themes $(92 \%)$ within the first 12 interviews only. The sample size of this study also supported by Morgan (2002) who found that the first five to six in-depth interviews produced the majority of new data, and approximately $80 \%$ to $92 \%$ of concepts were identified within the first 10 interviews. Morgan (2002) added that nearly no new concepts were found after 20 interviews.

\section{Research Technique}

Semi-structured interviews were used. Mason (2002) defined semi-structured interviews as a process of data generation where the interviewer plays an "active and reflexive" role. Questions are pre-determined, but the order and wording can be modified, and questions can be omitted or added during the interview, depending on the answers received from the interviewee (Robson, 2002). Additionally, qualitative interviews do not aim to standardize but instead achieve more in terms of "depth, nuance, complexity, and roundedness" of what is to be understood (Mason, 2002). This study is completely confidential by anonymizing participant backgrounds and they were given three options of how the interview can be done: face to face, phone interview, online communication. Due to the pandemic crisis of Covid-19 and the participants' requested to communicate online, most interviews were done through asynchronous online communication which involves interaction that is not time-bound (e.g. messaging online platform: WhatsApp and chatbox application) (Perveen, 2016). The time is taken during the asynchronous online communication range from three hours to 24 hours. Two interviews were conducted face to face and that the time took approximately about 25 minutes.

\section{Research Technique and Data Analysis}

Thematic analysis was used in this study, which is summarised as a process of developing codes, identifying themes, and analytical summary in qualitative data (Braun \& Clarke, 2006; Guest, MacQueen \& Namey, 2012; Maguire \& Brid Delahunt, 2017). The goal of thematic analysis is to identify themes (i.e. patterns in the data that are important or interesting) and use these themes to address the research or say something about an issue. This is much more than simply summarising the data; a good thematic analysis interprets and makes sense of it (Maguire \& Delahunt, 2017). The following table 1 explained further how we used the thematic analysis recommended by Cruzes and Dyba (2011).

Table 1: Thematic Analysis of Study

\begin{tabular}{ll}
\hline Analytic Steps & Descriptions \\
\hline Extracting Data & $\begin{array}{l}\text { Transcribed the interview into text with careful editing to maintain } \\
\text { accuracy and re-checking for verification purposes. The study used the } \\
\text { premises of this information to build a general overview of the topic and } \\
\text { structured research around this. }\end{array}$ \\
\hline Generating Codes & $\begin{array}{l}\text { Generating codes for finding relevant ideas and organized the data in a } \\
\text { meaningful and systematic way. First, all information given was } \\
\text { transcribed into Microsoft office-words. Generating initial codes was } \\
\text { done by coding every segment of the text. Then, we searched for the } \\
\text { most frequent or significant codes to answer the research question of } \\
\text { this study. }\end{array}$ \\
\hline $\begin{array}{l}\text { Translating } \\
\text { Themes }\end{array}$ & $\begin{array}{l}\text { In this step, we categories the coded data based on thematic or } \\
\text { conceptual similarity. Identified research themes based on two levels: } \\
\text { semantic (identify the explicit and surface meanings of the data) and } \\
\text { latent (capture underlying ideas, patterns, and assumptions). This step is } \\
\text { important to make sure the themes were coherent and distinct to one } \\
\text { another and worked accordingly to the codes provided. }\end{array}$ \\
\hline $\begin{array}{l}\text { Create a model of higher- } \\
\text { order themes }\end{array}$ & $\begin{array}{l}\text { Explore relationships between themes and create a model of higher- } \\
\text { order themes. This step is important to make sure the themes are }\end{array}$ \\
\hline
\end{tabular}


coherent and distinct to one another and work according to the codes provided. There were considerable overlaps between steps 2, 3, and 4 .

\begin{tabular}{ll}
\hline Trustworthiness & $\begin{array}{l}\text { Assess the trustworthiness of the interpretations leading up to the } \\
\text { thematic synthesis. }\end{array}$ \\
\hline
\end{tabular}

\section{RESULTS/FINDINGS}

This section presents the results of thematic analysis by presenting findings of HR and MA integration in delivering organizational working flexibility strategy. Next, the study further deliberated the key lessons learned from the findings of the first research objective to develop a conceptual framework for HR and MA integration, so that FWA implementation or enhancement can be both effective and efficient.

\section{Overlapping responsibilities between $\mathrm{HR}$ and $M A$}

The study has identified that all participants in this study agreed that HR and MA should have a close working relationship because of their overlapping responsibilities. The integration of both HR and MA in designing the FWA plan will be very useful to the organizations. The followings were some of the participants' remarks:

"The integration between HR and MA is very useful because manpower cost is just like an iceberg, it is not solely about payroll. HR and MA integration enable us to record and track every single cost such as return on investment, total remuneration package, and every single headcount cost." (PHR1)

"Management accounting can predict future finances, so they are good in decisions makes in terms of cost. Regarding work-life balance, women especially might quit from their career if there is no work-life balance provided. This work-life balance emerges from FWA. Management accounting knows total loss. MA knows wages prediction that suitable. MA in the management talent pool may help HR to plan strategically for FWA." (PHR2)

"So far HR and accounting are two separate decisions in an organization. Mainly, HR makes decisions related to people, and accounting is just processing the payment and taking care of financial records. There is a missing link between accounting or finance people involved in HR decision making. It is hard to find HR people with an accounting background. Integrating both HR and MA is very good because HR needs more information on budgeting, financial projection, and more details accounting formulation." (PHRAC1)

"Accounting information is very important for HR in managing FWA as it helps HR to prepare financial statements, cash flow, increase corporate governance and monitoring FWA cost, and evaluate actual performance in light of the original and amended plans. MA can assist HR to take necessary measures, whether remedial or modified the FWA plan and then achieving the required goals effectively and efficiently." (PAC1)

"HR needs Management accounting in managing people and HR decision making because MA provides an overall overview of the strategic planning of a firm, while HR will be an integral part of the overall budgeting. There must be a synchronization between the two to achieve greater strategic performance." (PAC2)

"Although HR and accounting might work in different departments, their roles in some of the points intersect with one another. It is hard to say that these two organizational functions work independently, the collaboration between HR and accounting within that same organization is undeniable." (PHRAC2)

\section{The Intersection Point between HR and MA}

As a part of HR strategic planning in implementing FWA, this study has found that organizational HR implemented FWA as a talent management strategy that aimed to build and retain talent pool and developing the workforce to achieve organizational goals.

"When we talked about HR in managing people with flexible working, the aims will be on creating the talent pool which includes hiring, developing, and retaining employees. Employees in today's world having high social demand, and that required them to have flexible work so that they can be more productive and managing their work-life balance." - (PHRAC2)

"FWA is one part of retention programs, people want work-life balance, they didn't expect the benefit that gains in the future. People preferred to gain the benefits right away for example from FWA they can have work-life balance." - (PHR2)

Important remarks of study findings highlight that MA information is very important in managing talent.

"MA can help HR in talent management. For example, through MA, HR can predict whether it's worth hiring new employees or retain an existing one. This working relationship will enable us to hire the right person with the right budget." - (PHRI)

"HR will need managerial and cost accounting report for the cost of worker and make decisions accordingly to organizational financial resources." (PAC1) 
"Major concern which many corporations across the organization are facing is associated with high people cost. Managerial accounting report is very useful for the report related to training expenditure and labor cost of hiring, retiring or retaining" (PAC3)

"MA emphasis on the learning and growth within the firm, informing the HR what more is needed from the employees for example enhancing the competencies and other related skills to further improving and achieving firm's goals. Hence, providing insight into the training employees relevant to the need of the firm." -(PAC2)

Most of the participants also expressed their views that performance appraisal is one of the vital action plans in managing employees with FWA.

"Once an organization decided to offer FWA, employees' performance is vital to assess an employee's job performance within a flexible working environment. An evaluation system to assess FWA implementation must be created to oversee how effective FWA has been implemented in an organization." - (PHRAC2)

"Integration between $H R$ and MA is useful for performance measurement, especially for-profit oriented company; every single cent is count. What you give you get back, but there must be a clear policy on how HR works with MA." - (PHRI)

Participants with accounting background added that

"There must be a synchronization between the HR and accounting department to achieve greater strategic performance. MA provides information on whether each division is performing at its optimum capacity. Efficiencies include employees' productivity and such info is need by HR to make decisions on employees' productivity." - (PAC2)

"Comparison between historical data and budgeted/forecasted figure will make the HR department determine how performance indicators of employees are to be altered. Along with that, it provides additional guidelines as to where a significant improvement in the performance of employees is required in the future and which are the areas where employees are not working up to the standard." - (PAC3)

"Accounting information can assist the HR team to make wise decisions in terms of the right number to be hired which can maximize the capabilities of such organization." (PHRAC4)

Participants of the study also shared their view on compensation and benefits, which is significantly related to employees' performance.

"It's highly related when accounting predicts financing while HR managing people. They need to operate together, cannot split up. As compensation and benefits, accounting knows more rather than HR. Accounting information might help and can guide HR to have more clear direction on managing people. More clear and convincing. Compensation under HR, member need to know accounting to make accounting work in the HR department. If we have a clear instrument/guideline of how MA and HR work together, the FWA proposal will be more convincing." - (PHR2)

"HR is not complete without accounting information, for example, payroll needs accounting background. It's hard to find HR people who like payroll. So, normally we hired someone with an accounting qualification but she or he will be sitting under the HR department. People with an accounting background is more familiar and details with accounting formulation." (PHRAC1)

"HR needs at least basic management accounting in terms of so many things. For example, payroll decision making, employee benefits for example like annual leave calculation, long term of service calculation termination in lieu of notice et cetera. These are some portions of accounting understanding in HR decision making and also in managing people. It serves as the crucial part of HR for which this could guarantee an HR person manages to develop their job performance because they possess this kind of skill/knowledge at the workplace." (PHRAC3)

"For divisional level, HR managers will receive reports related to overtime, productivity, hours worked, an idle hour on a weekly/monthly/yearly basis, allowances allowed as well as training expenditure to the percentage of gross salary received/hours worked, etc. These reports will act as a control for the company and particularly $H R$ which will critically evaluate as employees are underperforming or not. Whether cost being incurred in exchange for service rendered by employees is adequate or not. Whether the employee is working and had met the anticipated targets. These all factors are assessed through accounting management reports" - (PAC3)

It is also reported that implementing FWA may require the existing job to be redesigned and may embedded technology in the new way of working

"Putting people into flexible work may incur additional cost such as embedded new technology. Does the organization have enough financial resources for this transformation? If there is an available resource, we 
need a financial projection report to forecast good return on investment or return on labor as results from FWA implementation." (PHRAC2)

One of the most important accounting information in FWA planning is budgeting

"MA provides an overall overview of the strategic planning of a firm, while HR will be an integral part of the overall budgeting.MA supplies info regarding the overall budgeting and strategic plan of a firm, while HR is part of the budgeting proposed within the MA budgeting. Hence, MA shall assist HR on the available allocation of resources such as total funds allocation. Managerial support in linking HR strategic to overall firm's strategic outcome." (PAC2)

"It is vital that there should be a participation of the human resource department while preparation of a budget for the next whole year. The reason is that budget is a guideline from which budgets are allocated to other departments. It will enable the human resource department to acknowledge the total funds allocated to the department for the next whole year. Along with that, the human resource department representative can respond to any grievances if exist on fund allocation or amount of resources allocated for employee recruitment, retention, and clearance from the job." - (PAC3)

"MA report or information is very useful for HR because it will help management to manage people better with an accurate budget." (PHRI)

Apart from budgeting, the findings also highlight that return on investment, variance analysis, and cost monitoring is the management accounting information, which is important to ensure that FWA implementation can be both effective and efficient.

"MA information to HR is very useful as it helps HR to record and track every single HR cost. When HR knows $H R$ costs, it enables HR to plan a total remuneration package (TRP) and estimate the return of investment (ROI). - (PHRI)

"Without MA information, there will be a missing piece in HR proposal. For FWA to be implemented we need accurate estimation on labor cost and determine whether it is worth investing in FWA and the overall cost of FWA implementation." (PHRAC2)

"MA is needed as part of the monitoring process; this includes activities from adopting FWA plan and communicating them from the higher to lower-level people in the organization. Actual performance in light of the original and amended plan. Variance analysis will be needed in this case and take necessary measures, whether remedial or modified. Achieving the required goals effectively and efficiently." (PAC1)

"FWA requires a lot of direct and indirect monitoring, which can be very costly. MA can assist in setting up budgets and targets for comparison, provide effectiveness and efficiency analysis, planning, and costing for possible expansion of operation if FWA is proven to be beneficial." - (PAC4)

"Based on my experience, it is very useful for HR to have at least basic accounting knowledge in managing flexible work, be it big or small project." (PHRAC3)

\section{Strategic Outcomes of HR and MA integration in FWA}

All participants were agreed that integration between HR and MA in creating a flexible working strategy provides a clear strategic link between HR outcomes and business results. The followings were some of the participants' comments:

"HR outcome is significant and contribute to business performance, while MA may translate such performance linked to the overall business performance." - (PAC2)

"HR is about people and their effectiveness, integrating management accounting into HR help FWA plan not merely on the effectiveness of the program but also accentuating on the efficiency of the FWA." - (PHRAC2)

"At the end of the process, the result of the HR side will be way too fast achieved than those without MA." (PHRAC3)

"The connection between HR and MA will bridge the gap between HR and organizational outcomes." (PHRAC5)

Most of the participants also agreed that integrating MA into HR's FWA plan potentially yield effective HR cost and saving exercise.

"Management accountant has its role to play at the executive and divisional level. Because at the executive level, Management accountants perform a cost-benefit analysis and provide valuable information when new strategies were formulated for the decision-making process." (PAC3)

"When HR and MA work together cost related to FWA can be utilized an efficient way and time saving too." (PHRAC3) 
"HR proposal, particularly in FWA, can be managed more precisely by looking at the projection of HR cost when implementing FWA." - (PHRAC2)

"HR and MA integration is reliable, through MA corporate governance can be improved, managing cash flows, and preparing financial statements." - (PAC1)

"MA will enable HR to see HR related cost crystal clear and exercising in a way that can save HR budget" (PHRAC5)

The positive response from overall participants indicated that HR and MA integration capable to build a strategic return of investment on FWA implementation.

"More strategic ROI due to effective planning between HR combining with Management Accounting." (PHRAC3)

"MA report can assist HR to have a right measure to ROI or ROL." (PHRAC2)

"HR and MA integration enable us to record and track every single cost such as return on investment." (PHR1)

"Integrating HR and accounting side will potentially lead to a great return on employees." - (PHRAC5)

The implementation of FWA has long been recognized as a strategy for hiring, developing, and retaining talent. Most of the participants believed that the realignment between HR and MA will promote a dynamic acquisition strategy.

"MA report or information is very useful for HR because it will help management to manage people better with an accurate budget." (PHRI)

"Hiring employees can be done in the right budget and both HR And account people can discuss together a rewarding performance which helps to develop and maintaining organization current talent pool." - (PHRAC2)

"Recruitment and retention of employees can be managed in both effective and efficient ways, and that will optimize organizational capabilities." (PHRAC5)

Another strategic outcome expected from HR and MA integration is that it provides comprehensive qualitative and quantitative performance management

"Embedding management accounting into HR captured how FWA can be applied to improve business performance and measure the efficiency of FWA and potential credible value of implementing FWA. (PHRAC2)

"There must be a synchronization between the two to achieve greater strategic performance". - (PAC2)

"Also serves as a good benchmark and indicator on evaluating HR performance in producing high productivity." - (PHRAC2)

"Performance can be measured accurately because when HR and MA are combined it will cover both people and financial aspects." - (PHRAC5)

To conclude, the realignment between HR and MA is expected to generate five positive results or strategic outcomes: provides a clear strategic link between HR outcomes and business results, effective HR cost and saving exercise, strategic return of investment on FWA implementation, Comprehensive qualitative and quantitative performance management.

\section{DISCUSSION}

The current study found that HR and MA have overlapping responsibilities, both of these organizational functions should have a close working relationship to create a more effective and efficient FWA plan. HR needs MA in managing people and ensure that the HR decisions are prudent and farsighted. MA information not merely for a financial statement but is very useful for financial projection, budgeting, and cost control related to FWA. It is interesting to note that, HR and accounting might work in different departments, but their roles in some of the points intersect with one another and the collaboration between HR and accounting within that same organization is undeniable.

As a part of HR strategic planning in implementing FWA, the current study found that HR targets in implementing FWA are to strengthen the organization's talent pool which includes attracting, developing, and retaining talent to achieve organizational goals. This finding is in agreement with previous studies (e.g. Kossek et.al., 2014; Burgmann, 2012) which highlighted the implementation of FWA is often related to attracting and retaining the organizational talent pool. Important remarks of study findings highlight that MA information is very important in managing talent. For example, through accounting information organizations will be able to estimate the direct financial costs associated with hiring, losing employees as well as training replacement needed due to employee turnover.

The findings of the current study are consistent with those of Iqbal et al.,(2010) who asserted that the most important managerial function is to add value to currently available human capital by scheming and executing effective and viable 
human resource development plans. Hence, to implement FWA as part of the strategic goal of an organization, HR is expected to be able to supply information about the measurement of the cost and value of people from a human factor's perspective (Iqbal et al.,2010). This result also corroborates with the findings of Kotey and Sharma (2019) who found that FWA directly increased ROL and indirectly through a reduction in staff turnover.

Another important finding highlighted that, there is a definite prerequisite for HR and MA to sit together to manage performance appraisal of the employees. For example, an evaluation system to assess FWA implementation must be created and there should be a clear policy of how employees are assessed and how it links to rewards and considering the financial resource of the organization. Also, the study findings stressed that a comparison between historical data and budgeted/forecasted figures will make the HR department determine as to how performance indicators of employees are to be altered. This result is in line with Nguwi (2017) who asserted that is vital to clearly outline the performance goals and implementation methodology of a system like FWA because, without a clear policy, performance management risks becoming an abstract exercise that will likely fail. After all, no clear guideline to management, and the employees will also be left in blurred information.

Corroborate with the previous finding, the current study also presents evidence that HR and MA do not merely collaborate on performance measurement but also the related matter to compensation and benefits. The evidence of the study supported that HR payroll will need basic accounting knowledge to identify and measuring data related to employee's compensation and benefits as well as matching the cost and revenues of the business. These results corroborate with the findings of Zeng (2018) and, which highlighted the reciprocal interaction between HR and MA.

Another outcome highlighted in this study is related to redesigning the current job to match with a new implementation of FWA in an organization. This is also consistent with Armstrong (2006) because FWA might include content related to the job's other basic requirements of executing and scheduling tasks. MA information is important to HR because as reported in the result of this study, it accentuated that FWA may incur additional costs such as embedded new technology. At the same time, FWA may also consider space-saving and that will also be resulting in saving cost exercise. For instance, a firm with a total of 30 employees would require at least an estimated average office space of 7,500 square feet (assuming 30 people x 250 square-feet/employee). Once the organization executes FWA, with half of the employees have an option to work from home or alternative work schedule, thus, the total space required is now only as much as 3,750 square feet, as the firm need not accommodate all 30 employees at one time.

The current study also shows that MA partnership with HR is critical. First, in terms of budgeting, the result of this study heightened that MA provides an overall overview of the strategic planning of a firm, while HR will be an integral part of the overall budgeting. Besides, return on investment, variance analysis, and cost monitoring is the management accounting information, which is important to ensure that FWA implementation can be both effective and efficient. Without MA information, there will be a missing piece in the HR proposal. The most convincing FWA implementation plan must be able to specify the effectiveness and efficiency of the program. All in all, almost all of the participants agreed that the realignment between HR and MA will potentially generate positive results such as a clear strategic link between HR outcomes and business results, effective HR cost and saving exercise, strategic return of investment on FWA implementation, Comprehensive qualitative and quantitative performance management.

\section{A Proposed Conceptual Framework of HR and MA for strategic FWA Outcomes}

Based on the findings and discussion above, a conceptual framework has been developed to enable management or organizational HR to have a fast but comprehensive view of HR and MA integrations points and the expected strategic outcomes of FWA implementation (see Figure 1 below).

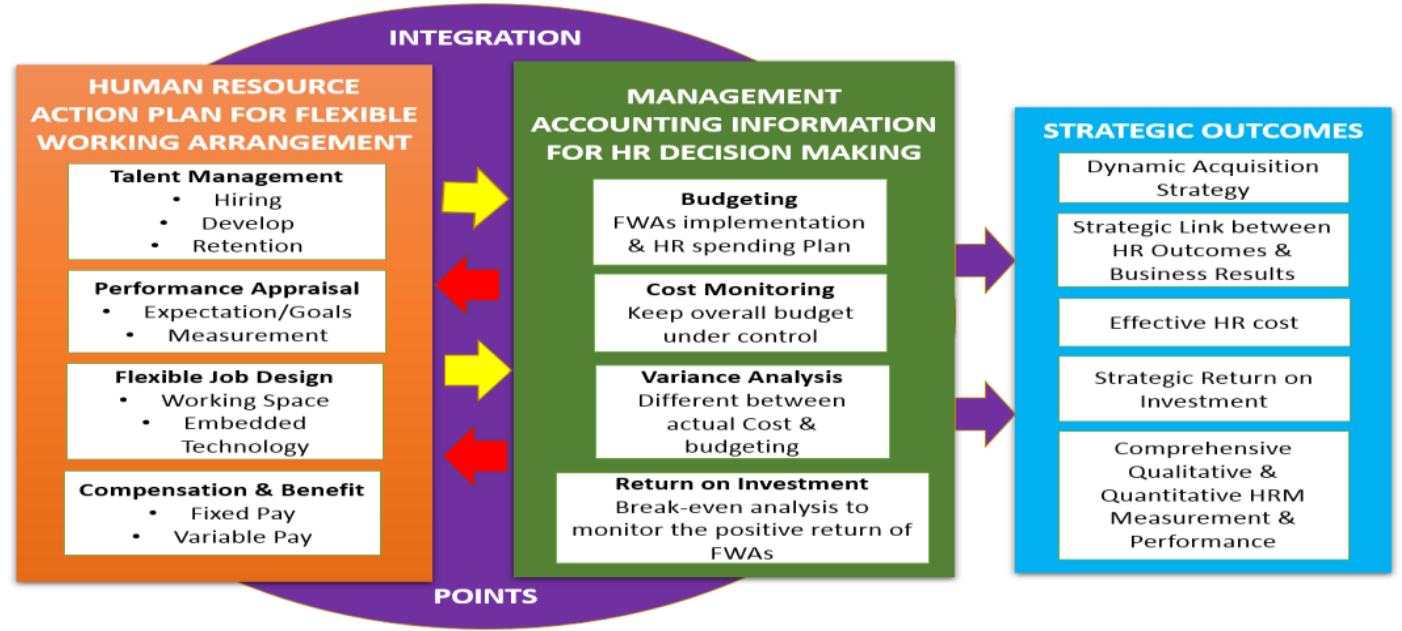

Figure 1: A conceptual Framework of HR and MA integration and FWA strategic outcomes 
This conceptual framework unified both quantitative (financial efficiency) and qualitative (HR effectiveness) perspectives in implementing or enhancing FWA in an organization. Additionally, this conceptual model proposed that flexibility strategy must also be centred on people to a business-focused approach. People management and FWA implementation cannot be left solely to HR. The conceptual model of this study emphasis that HR alignment involves the collaboration and devolution of HR and MA to ensure the effectiveness of FWA through the building of constructive relationships and enhancing the standard of strategic decisions.

As illustrated in Figure 1, the orange box indicated the HR action plan in FWA implementation which included talent management, performance appraisal, flexible job design, and compensation and benefits. The implementation of FWA is often related to attracting and retaining the organizational talent pool (e.g. Kossek et.al., 2014; Burgmann,2012). Attraction, retention, and career management (employee's development) explicated under the dimension of talent management strategies as clustered in Armstrong (2006) HRM handbook. Most of the HR participants in this study assumed that MA information will facilitate HR in managing HR costs such as recruitment, training (employee's development), and retaining employees. In addition to that, most of the HR participants emphasized that HR needs at least basic accounting to manage employees' compensation and benefits, or else, HR may need to hire someone with an accounting background. The integration between HR and MA is expected to contribute to a dynamic acquisition strategy and having an effective HR cost.

Implementing or upgrading existing FWA in an organization may require the current tasks of employees to be redesigned, which might include content related to the job's other basic requirements of executing and scheduling tasks (Armstrong, 2006). As indicated in the result of the study, FWA may incur additional costs such as embedded new technology, but it may also offer saving cost exercise because FWA may result in space-saving. The synergy between MA and HRM is significant to have a greater impact on internal business process performance such as improves production efficiency, cost savings, quality improvement, and increased asset utilization (Tavitiyaman et al., 2012; Bititci et al., 2011). This can be achieved through competent human resources coupled with accurate and reliable management accounting information (Hutahayan, 2020).

The first and important MA information in the FWA plan is budgeting which involves the activity of planning for future financial. Firms do budgeting for operational planning, performance evaluation, communication of goals, controlling and co-ordinating resources (Apostolides, 2016). The HR shall be able to communicate the resources needed and cost expected to be incurred for any HR program such as FWA. Budget is essential because it helps the firm to have detailed planning processes and uncover potential problems before they occur and spot the omission and inconsistency of the plans (Cunningham et al., 2019).

MA information is also needed for cost monitoring purposes, which is important to keep FWA overall budget are under control. MA provides various control tools and mechanisms which is better known as Management Control Systems (MCS). This MCS is used as a strategic plan and control to achieve organizational objectives through objective setting and strategy formulation as well as taking steps to ensure that the employees do what is best for the organization (Merchant \& Van Deer Stede, 2017). MCS tools like planning, budgeting and forecasting, performance measurement, and reports (Novas et al., 2017) allows management to account for cost and monitor the performances of various business functions within an organization. Therefore, regarding FWA implementation, MCS is viable to account for successful FWA execution.

Bambrough (2003) outlines that costs associated with HR activities can be divided into four major categories, which are (1) cost of training materials, (2) cost of equipment and other facilities, (3) cost of trainees, and (4) trainers' fees. While FWA is to promote employees' wellbeing which in turn improves employees' productivity (Katz et.al, 2019; Hunter, 2019; Kuroda \& Yamamoto, 2018; Obisi, 2017), therefore, such a strategy can be considered as an investment which expected to yield high productivity, lower employees' turnover, thus reduce the cost of hiring and training new employees. The trade-off (increase/decrease) between various costs associated with FWA implementation shall be communicated to management and budgeting is therefore an effective and efficient way to evaluate the effect of FWA. It would be best to adopt flexible budgeting (FB) in contrast to a static budget, as FB adjusts to any changes in activity and that it presents cost information which allows for a variance analysis (Labro, 2019). Variance analysis assists management to examine whether the budgeted amount is following the plan, and any favorable and deficiencies in the budget analysis shall further assist the management to improve FWA implementation. This provides information to the firm on the have a better strategic plan to enhance firm performance both in the short and long run. Therefore, it is expected that MA integration with HR will provide a clear strategic link between HR outcomes and business results as well as the strategic return of investment on FWA implementation.

Last but not least, HR and MA integration is expected to provide comprehensive qualitative and quantitative performance management. Most of the prominent performance measurement in MA is using the Balance Score Card (BSC) as it portrays the overall performance of an organization. In fact, literature has documented that BSC is used to measure performance in HRM (see for example Gesuela, 2015; and Bachtiar, 2017). Moreover, Amirul et.al., (2019) have highlighted the interconnectedness between HR and MA utilizing this BSC. The BSC comprises of both financial and non-financial performance indicators which can be categorized into four metrics: (1) financial, (2) customers, (3) internal business process, (4) learning and growth (Kaplan, 2009; Tan \& Khodaverdi, 2017). Each metric has different 
KPI and organization, may develop the criteria or the KPI which can be tailored and flexible enough to further suit the firms' aims (Amirul et.al., 2019). The synchronization between HR and MA can be aligned through this BSC, whereby internal business processes concerns with employees' productivity and that learning and growth focus on employee improvement, which are the main function of HR. Therefore, both MA and HR are not working in a silo as both complementing one another to better achieve the organizational objectives in the long run. This can be done through strategic planning where the integration between these two is essential.

\section{CONCLUSION}

In conclusion, this study aims to advance the notion of FWA literature by unveiling the strategic alignment between HR and MA. It addresses the issues that lie within FWA research which overwhelming on the adoption of FWA, but the most pressing concern is that there is a huge gap in the existing literature of how this FWA can be strategically managed to further enhance the overall organizational performance, both financially and non-financially. Therefore, this study provides insight beyond FWA adoption, whereby we proposed a framework for strategic FWA, which bridges the connection between HR and MA so that FWA implementation or enhancement can be effective and efficient. We thoroughly discussed how the synergy between HR and MA can be achieved through several key elements, which is expected to yield strategic outcomes for the organization. Most importantly, the organization shall be able to overcome the redundancies between HR and MA roles to create more compelling strategic planning for FWA implementation. Hence, leading towards greater strategic outcomes such as strategic dynamic acquisition, effective HR cost, a strategic link between HR outcomes and business, strategic return on investment, as well as comprehensive HRM measurement and performance. We highlighted our key result findings that are the integration between HR and MA through the HR action plan for FWA like talent management, performance appraisal, flexible job design, and the compensation and benefits; with the MA control and tools such as budgeting, cost monitoring, variance analysis, and ROI. We also proposed the use of BSC as a key performance indicator to assess the overall outcome of FWA implementation.

\section{LIMITATION AND STUDY FORWARD}

The most important limitation lies in the fact of this study is the availability of literature combining both HR and MA. Thus, more studies are urged to delve far analyzing the possible integration between HR and MA, not only from the perspective of FWA but other areas. Thus, resulting in more hybrid integration between HR and MA from a broader perspective. Secondly, since this study merely proposing a strategic FWA framework, yet essential, thus it provides no empirical evidence on how this framework can function in the real business environment. Nonetheless, our framework assists researchers to advance this study by proposing innovative tools on how HR and MA may collaborate. Such innovative tools are important to better assist the organization to have more profound FWA implementation for longterm business operations.

\section{ACKNOWLEDGEMENT}

This research is funded under the fundamental research grant scheme by the Minister of Higher Education (MOHE) Malaysia, with the code of FRG0461-2017.

\section{AUTHORS CONTRIBUTION}

All co-authors have contributed accordingly to this article. The first author was the first to initiate the core research idea, analyzing the data, providing the discussion, and concluding remarks for this study. The second author was concentrating on providing a literature review related to this study. While the third author contributed to analyzing the data from the perspective of management accounting and responsible to review the whole paper.

\section{REFERENCES}

1. Amirul, S. M., Amirul, S. R., Anwar Abu Bakar, M. A., Mail, R., \& Dasan, J. (2019). Does Management Accounting Matters for Effective Flexible Working Arrangements Strategic Plan? Accounting Centre Accounting Research Series, Vol 1, 1-6.

2. Andrejic, N. (2017). An exploration of the individual strategies employed by flexibly working parents.

3. Apostolides, N. (2016). Management Accounting for Beginners. $1^{\text {st }}$ Ed. Routledge Focus on Business \& Management, London, and New York. https://doi.org/10.4324/9781315630410

4. Appelbaum, S. H., \& Hood, J. (1993). Accounting for the Firm's Human Resources. Managerial Auditing Journal, 8(2), 17-24. https://doi.org/10.1108/02686909310026440

5. Armstrong, M. (2006). A handbook of Human Resource Management Practice, 10th Edition, Kogan Page Ltd.

6. Bachtiar, M. (2017). Analysis of performance measurement at HR-GR Department using the balance scorecard method. In IOP Conference Series: Materials Science and Engineering (Vol. 277, No. 1, p. 012006). IOP Publishing. https://doi.org/10.1088/1757-899X/277/1/012006

7. Bambrough, J. (2003). The HR Management Manual, Training Your Staff, Penguin Book, London.

8. Barney, C. E., \& Elias, S. M. (2010). Flex-time as a moderator of the job stress-work motivation relationship: A three nation investigation. Personnel Review, 39(4), 487-502. https://doi.org/10.1108/00483481011045434 
9. Bell, A. S., Rajendran, D., \& Theiler, S. (2012). Job stress, wellbeing, work-life balance and work-life conflict among Australian academics. E-Journal of Applied Psychology, 8(1), 25-37. https://doi.org/10.7790/ejap.v8i1.320

10. Bititci, U. S., Ackermann, F., Ates, A., Davies, J., Garengo, P., Gibb, S., \& Shafti, F. (2011). Managerial processes: Business process that sustain performance. International Journal of Operations \& Production Management. https://doi.org/10.1108/01443571111153076

11. Braun, V. \& Clarke, V. (2006). Using thematic analysis in psychology. Qualitative Research in Psychology, 3 , 77-101.

12. Bannerman, B. (2003, June). Making HR a profit center: current technological advancements make it possible for human resource departments to play a strategic role in managing a company's key assets, its people. (Human Resources). Financial Executive, 19(4).

13. Burgmann, L. (2012). Managing in a Flexible work Environment. Australian Institute of Management. Retrieved from https://www.wgea.gov.au/sites/default/files/AIM-Managing-in-a-Flexible-WorkEnvironment.pdf

14. Caillier, J. G. (2018). Do flexible work schedules reduce turnover in U.S. federal agencies? Social Science Journal, 55(2), 108-115. https://doi.org/10.1016/j.soscij.2017.09.005

15. Cannon F. and Elford N. (2017) The Agility Mindset: How reframing flexible working delivers competitive advantage. Palgrave Macmillan. Cham, Switzerland. https://doi.org/10.1007/978-3-319-45519-8

16. Chartered Institute of Personnel and Development (CIPD). (2014). HR: Getting smart about agile working, (November).

17. Clake, R. (2005). Flexible working: the implementation challenge. CIPD, 3-60. Retrieved from http://www.cipd.co.uk/NR/rdonlyres/C3B8BDF1-3979-4B95-BF90A3C19521560D/0/flexwrkimpman1105.pdf

18. Clarke, V., Braun, V., \& Hayfield, N. (2015). Thematic analysis. Qualitative psychology: A practical guide to research methods, 222-248.

19. Coenen, M., \& Kok, R. A. W. (2014). Workplace flexibility and new product development performance: The role of telework and flexible work schedules. European Management Journal, 32(4), 564-576. https://doi.org/10.1016/j.emj.2013.12.003

20. Collier, S. J. (2009). Topologies of power: Foucault's analysis of political government beyond 'governmentality'. Theory, culture \& society, 26(6), 78-108. https://doi.org/10.1177/0263276409347694

21. Chandola, T., C. Booker, M. Kumari, and M. Benzeval.2019. "Are Flexible Work Arrangements Associatedwith Lower Levels of Chronic Stress-RelatedBiomarkers? A Study of 6025 Employees in the UKHousehold Longitudinal Study." Sociology 53 (4):779-799. https://doi.org/10.1177/0038038519826014

22. CPA Australia, (2012).

23. Creswell, J. W. (2009). Research Design: Qualitative, Quantitative, and Mixed Methods Approaches. $3^{\mathrm{rd}}$ ed. Sage Publications, Inc. http://doi.org/10.2307/1523157

24. Creswell., John, W., \& Plano Clark, V. L. (2011). Designing and Conducting Mixed Methods Research. $2^{\text {nd }}$ Ed. SAGE Publication.

25. Crouch, M., \& McKenzie, H. (2006). The logic of small samples in interview-based qualitative research. Social science information, 45(4), 483-499. https://doi.org/10.1177/0539018406069584

26. Cruzes, D. S., \& Dyba, T. (2011). Recommended steps for thematic synthesis in software engineering. In 2011 international symposium on empirical software engineering and measurement (pp. 275-284). IEEE. https://doi.org/10.1109/ESEM.2011.36

27. Cunningham, B. M., Nikolai, L. A., Bazley, J. D., Kavanagh, M., \& Simmons, S. (2019). Accounting information for business decisions (Third edition.). Cengage.

28. Currie, D. (2001). Managing Employee Well-Being, Chandos Publishing Oxford Limited, Oxford.

29. Daft, R. L., \& Marcic, D. (2020). Understanding management (11th ed.). Boston MA: Cengage.

30. Delery, J. E., \& Roumpi, D. (2017). Strategic human resource management, human capital and competitive advantage: Is the field going in circles? Human Resource Management Journal,27(1), 1-21. https://doi.org/10.1111/1748-8583.12137

31. De Menezes, L. M., \& Kelliher, C. (2011). Flexible working and performance: A systematic review of the evidence for a business case. International Journal of Management Reviews, 13(4), 452-474. https://doi.org/10.1111/j.1468-2370.2011.00301.x

32. De Menezes, L. M., \& Kelliher, C. (2017). Flexible Working, Individual Performance, and Employee Attitudes: Comparing Formal and Informal Arrangements. Human Resource Management, 56(6), 1051-1070. https://doi.org/10.1002/hrm.21822

33. Downes, C., \& Koekemoer, E. (2011). Work-life balance policies: Challenges and benefits associated with implementing flexitime. SA Journal of Human Resource Management, 9(1), 1-13. https://doi.org/10.4102/sajhrm.v9i1.382

34. Dworkin, S. L. (2012). Sample size policy for qualitative studies using in-depth interviews. https://doi.org/10.1007/s10508-012-0016-6

35. Gilabert, P. (2008). Global justice and poverty relief in nonideal circumstances. Social Theory and Practice, 34(3), 411-438. https://doi.org/10.5840/soctheorpract200834324 
36. Goga-Cooke, J. (2012). "The Benefits of Flexible Working Arrangements", Future Work Institute. Retrieved from https://www.bc.edu/content/dam/files/centers/cwf/individuals/pdf/benefitsCEOFlex.pdf

37. Guest, G., Bunce, A., \& Johnson, L. (2006). How many interviews are enough? An experiment with data saturation and variability. Field methods, 18(1), 59-82. https://doi.org/10.1177/1525822X05279903

38. Guest, G., MacQueen, K. M., \& Namey, E. E. (2012). Applied thematic analysis. Thousand Oaks, CA: SAGE Publications, Inc. doi: https://dx.doi.org/10.4135/9781483384436

39. Gesuele, B. (2015). Human Resource Measurement: A Balanced Scorecard Approach. Journal of Human Resource Management, 3(2), 28. https://doi.org/10.11648/j.jhrm.s.2015030201.14

40. Hartel, Charmine E. J. and Fujimoto, Yuka (2014). Human Resource Management. 3rd ed. Frenchs, NSW Australia: Pearson Education.

41. Haque, A. (2020), "Strategic HRM and organisational performance: does turnover intention matter?", International Journal of Organizational Analysis, In Press. https://doi.org/10.1108/IJOA-09-2019-1877

42. Hayman, J. R. (2009). Flexible work arrangements: Exploring the linkages between perceived usability of flexible work schedules and work/life balance. Community, Work \& Family, 12(March 2013), 327-338. http://doi.org/10.1080/13668800902966331

43. Hays (2017), "Asia braces for change: tailoring talent strategies for uncertainty", in Wright, C. (10Ed.), Singapore.

44. Hunter, P. (2019). Remote working in research: An increasing usage of flexible work arrangements can improve productivity and creativity. EMBO Reports, 20(1). https://doi.org/10.15252/embr.201847435

45. Hutahayan, B. (2020). The mediating role of human capital and management accounting information system in the relationship between innovation strategy and internal process performance and the impact on corporate financial performance. Benchmarking, 27(4), 1289-1318. https://doi.org/10.1108/BIJ-02-2018-0034

46. Iqbal Chaudhry, N., \& Azam Roomi, M. (2010). Accounting for the development of human capital in manufacturing organizations. Journal of Human Resource Costing \& Accounting, 14(3), 178-195. https://doi.org/10.1108/14013381011095463

47. Jones, D. M. C. (1973). Accounting for human assets. Management Decision, 11(3), $183-194$. https://doi.org/10.1108/eb001021

48. Katou, A.A. (2017), "How does human resource management influence organisational performance? An integrative approach-based analysis", International Journal of Productivity and Performance Management, Vol. 66 No. 6, pp. 797-821. https://doi.org/10.1108/IJPPM-01-2016-0004

49. Kaplan, R. S. (2009). Conceptual Foundations of the Balanced Scorecard. Handbooks of Management Accounting Research, 3, 1253-1269. https://doi.org/10.1016/S1751-3243(07)03003-9

50. Kariyawasam, D.H. (2016). Relationship between Accounting Information and Human Resource Management Related Strategic Decision Making in Sri Lankan Manufacturing Companies. International Journal of Business and Management Invention. 5 (12)1-5.

51. Katz, L. F., \& Krueger, A. B. (2019). The rise and nature of alternative work arrangements in the United States, 1995-2015. ILR Review, 72(2), 382-416. https://doi.org/10.1177/0019793918820008

52. Kossek, E. E., \& Michel, J. (2010). Flexible work schedules. Handbook of industrial-organizational psychology, 1, 535-72. https://doi.org/10.1037/12169-017

53. Kossek, E. E., Valcour, M., \& Lirio, P. (2014). The sustainable workforce: Organizational strategies for promoting work-life balance and wellbeing. In C. Cooper, \& P.Chen (Eds.), Work and wellbeing(pp. 295-318). Oxford, UK: Wiley-Blackwell. https://doi.org/10.1002/9781118539415.wbwell030

54. Kotey, B. A. (2017). Flexible working arrangements and strategic positions in SMEs. Personnel Review, 46(2), 355-370. https://doi.org/10.1108/PR-04-2015-0089

55. Kotey, B. A., \& Sharma, B. (2019). Pathways from flexible work arrangements to financial performance. Personnel Review, 48(3), 731-747. https://doi.org/10.1108/PR-11-2017-0353

56. Kowalski, T. H. P. \& Loretto, W. (2017) Wellbeing and HRM in the changing workplace, The International Journal of Human Resource Management, 28:16, 2229-2255, DOI: https//:10.1080/09585192.2017.1345205

57. Kuroda, S, and I Yamamoto (2018), "Good boss, bad boss, workers' mental health and productivity: Evidence from Japan", Japan and the World Economy 48: 106-118. https://doi.org/10.1016/j.japwor.2018.08.002

58. Labro, E. (2019). Costing systems. Foundations and Trends in Accounting, 13(3-4), $267-404$. https://doi.org/10.1561/1400000058

59. Ladda, R. L. (2014). Nature of the Audit, $1^{\text {st }}$ Ed. Laxmi Book Publication, Solapur, India.

60. Lake, Andy (2013). Smarter government and its impacts. Chapters in Smart flexibility (1st ed., pp. 207- 229). Gower Publishing Limited.

61. Lewis, Suzan and Roper, Ian (2008) Flexibility and work-life balance. In: Human resource management: a case study approach. Muller- Camen, Michael and Croucher, Richard and Leigh, Susan, eds. Chartered Institute of Personnel and Development, London, pp. 181- 199.

62. Lee, S.-Y., \& Hong, J. H. (2011). Does Family-Friendly Policy Matter? Testing Its Impact on Turnover and Performanceon. Public Administration Review, 71(6), 870-879. http://www.jstor.org/stable/41317386 
63. Loon, M., Otaye-Ebede, L, \& Stewart, J. (2019) The paradox of employee psychological wellbeing practices: an integrative literature review and new directions for research, The International Journal of Human Resource Management, 30:1, 156-187, DOI: https://doi.10.1080/09585192.2018.1479877

64. Maguire, M., \& Delahunt, B. (2017). Doing a Thematic Analysis: A Practical, Step-by-Step Guide for Learning and Teaching Scholars. *. All Ireland Journal of Teaching and Learning in Higher Education , 8(3), 335133514. http://ojs.aishe.org/index.php/aishe-j/article/view/335

65. Mason, J. (2002). Qualitative researching, (2nd edn). Sage Publications, London.

66. Maxwell, G., Rankine, L., Bell, S., \& MacVicar, A. (2007). 'The Incidence and Impact of Flexible Working Arrangements in Smaller Businesses'. Employee Relations, 29, 2, $138-161$. https://doi.org/10.1108/01425450710719987

67. Merchant, Kenneth A, \& Van der Stede, Wim A. (2017). Management control systems: performance measurement, evaluation, and incentives (Fourth edition.). Pearson Education Limited.

68. Morgan, D. L. (2002). Handbook of interview research: Context and method.

69. Nguwi, Memory. (2017). HR Perspective: Best Practice in Developing A Performance Management Policy. http://www.financialgazette.co.zw/hr-perspective-best-practice-in-developing-a-performance-managementpolicy/

70. Novas, J. C., Alves, M. do C. G., \& Sousa, A. (2017). The role of management accounting systems in the development of intellectual capital. Journal of Intellectual Capital, 18(2), 286-315. https://doi.org/10.1108/JIC08-2016-0079

71. Obisi, C. (2017). Impact of Flexible Work Arrangement on Employees Performance in Public Schools in Lagos State, Nigeria. BVIMSR's Journal of Management Research, 9(2), 157-166. http://search.proquest.com/docview/1961322629/

72. Ollo-lopez, A., \& Bayo-moriones, A. (2010). The Relationship between New Work Practices and Employee Effort, 219-235. https://doi.org/10.1177/0022185609359446

73. Orly, Shapira-Lishchinsky. (2015). Simulation-based constructivist approach for education leaders. Educational Management Administration \& Leadership, 43(6), 972-988. https://doi.org/10.1177/1741143214543203

74. Perveen, A. (2016). Synchronous and asynchronous e-language learning: A case study of virtual university of Pakistan. Open Praxis, 8 (1), 21-39. https://doi.org/10.5944/openpraxis.8.1.212

75. Tavitiyaman, P., Qiu Zhang, H. and Qu, H. (2012), "The effect of competitive strategies and organizational structure on hotel performance", International Journal of Contemporary Hospitality Management, Vol. 24 No. 1, pp. 140-159. https://doi.org/10.1108/09596111211197845

76. Potter, L. (2007). UK skills: making the grade. British Chambers of Commerce, London.

77. Quintero, A. H., \& Rosario, H. (2016). Math makes sense! a constructivist approach to the teaching and learning of mathematics. Imperial College Press; Distributed by World Scientific Publishing Co Pte Ltd. https://doi.org/10.1142/p1056

78. Richardson, J., \& Mckenna, S. (2014). Reordering Spatial and Social Relations: A Case Study of Professional and Managerial Flexworkers, 25, 724-736. https://doi.org/10.1111/1467-8551.12017

79. Robson, C. 2002. Research in the Real World, 2nd ed. Blackwell.

80. Scholarios,D., Hesselgreaves, H., Pratt, R. (2017) Unpredictable working time, wellbeing and health in the police service, The International Journal of Human Resource Management, 28:16, 2275-2298. https://doi.org/10.1080/09585192.2017.1314314

81. Saukkonen, N., Laine, T., \& Suomala, P. (2018). Utilizing management accounting information for decisionmaking. Qualitative Research in Accounting \& Management, 15(2), 181-205. https://doi.org/10.1108/QRAM$\underline{01-2017-0007}$

82. Society Human Resource Management (2016). SHRM Survey Findings: 2016 Strategic Benefits-Flexible Work Arrangements. https://www.shrm.org/hr-today/trends-and-forecasting/research-and-surveys/Documents/ SHRM-Survey-Findings-Strategic-Benefits-Flexible-Work-Arrangements.pdf

83. Stavrou, E., Spiliotis, S., \& Charalambous, C. (2010). Flexible working arrangements in context: an empirical investigation through self-organizing maps. European Journal of Operational Research, 202(3), 893-902. http://doi.org/10.1016/j.ejor.2009.06.021

84. Tan, Y., Zhang, Y. \& Khodaverdi, R. (2017) Service performance evaluation using data envelopment analysis and balance scorecard approach: an application to automotive industry. Ann Oper Res 248, 449-470. https://doi.org/10.1007/s10479-016-2196-2

85. Theeke, H. A. (2005). A human resource accounting transmission: shifting from failure to a future. Journal of Human Resource Costing \& Accounting, 9(1), 40-59. https://doi.org/10.1108/14013380510636694

86. Thomson, P. (2008). "The business benefits of flexible working". Strategic HR Review, Vol.7 No.2, pp.17-22. https://doi.org/10.1108/14754390810853129

87. Vedd, R., \& Kouhy, R. (2001). Management accounting and strategic human resource management: A UK/Canadian comparative analysis. Journal of Applied Accounting Research, 6(2), 90-120. https://doi.org/10.1108/96754260180001029

88. Zeng, H. (2018) Reciprocal Interaction between Management Accounting and Other Management Roles. Open Access Library Journal, 5, 1-8. https://doi.org/10.4236/oalib.1104908 